\title{
Two new species of the Hypostomus cochliodon group (Siluriformes: Loricariidae) from the rio Negro basin in Brazil
}

\author{
Pedro Hollanda Carvalho ${ }^{1}$, Flávio C.T. Lima ${ }^{1}$ and Cláudio H. Zawadzki²
}

Two new species of Hypostomus are described from the middle and upper rio Negro in Brazil. They are assigned to the Hypostomus cochliodon group (sensu Armbruster, 2003) by possessing few spoon-shaped teeth, and dentary angle averaging less than $80^{\circ}$. Hypostomus kopeyaka is described from the rio Tiquié, a tributary of the rio Uaupés, upper rio Negro basin, presents a unique color pattern among the Hypostomus species belonging to the Hypostomus cochliodon group, consisting of conspicuously horizontally elongated, closely-set black spots over the entire dorsal and lateral surfaces of the body. Hypostomus weberi is described from the middle rio Negro and can be distinguished from all remaining Hypostomus species belonging to the Hypostomus cochliodon group by possessing a unique color pattern consisting in large, rounded, widelyspaced black spots over body and fins.

Duas novas espécies de Hypostomus são descritas para a bacia do alto e médio rio Negro no Brasil. Elas são atribuídas ao grupo Hypostomus cochliodon (sensu Armbruster, 2003) por possuírem poucos dentes, em forma de colher e ângulo entre os dentários menor que $80^{\circ}$. Hypostomus kopeyaka, descrita do rio Tiquié, um afluente do rio Uaupés, bacia do alto rio Negro, apresenta um padrão de colorido único entre as espécies de Hypostomus pertencentes ao grupo Hypostomus cochliodon, que consiste em manchas escuras conspícuas horizontalmente alongadas e próximas entre si sobre toda a superfície dorso-lateral do corpo. Hypostomus weberi, descrita do médio rio Negro, é distinguida de todas as espécies de Hypostomus pertencentes ao grupo Hypostomus cochliodon por possuir um padrão de colorido único que consiste em grandes manchas escuras e arredondadas, relativamente afastadas entre si, sobre toda a superfície do corpo e nadadeiras.

Key words: Hypostomus kopeyaka, Hypostomus weberi, Hypostomus micromaculatus, Rio Tiquié, Amazon basin.

\section{Introduction}

The Hypostomus cochliodon group is a monophyletic entity (Montoya Burgos et al., 2002; Weber \& Montoya Burgos, 2002; Armbruster, 2003; Armbruster \& de Souza, 2005), distributed across Trans-andean South America (río Magdalena, río Atrato, and lago de Maracaibo basins), and Cis-Andean South America from coastal drainages of northern Venezuela to the rio Paraguay basin (Armbruster, 2003; Hollanda Carvalho \& Weber, 2004; Armbruster \& de Souza, 2005). The majority of the species belonging to this group, 13 of the 17 currently recognized as valid, are reported from the Amazon basin (Armbruster, 2003; Hollanda Carvalho \& Weber, 2004; Armbruster \& de Souza, 2005). The presence of the Hypostomus cochliodon group across both Trans- and CisAndean South America indicates that the group had diversified before the uplift of the Merida Andes, which established the present watershed divide between the Lago de Maracaibo and rio Orinoco basins, during the late Miocene (8 M.a.; Montoya-Burgos, 2003; Albert et al., 2006).

Three species belonging to the Hypostomus cochliodon group were reported from the upper rio Negro basin in Venezuela and Guyana: H. hemicochliodon Armbruster, $H$. macushi Armbruster \& de Souza, and H. sculpodon Armbruster (Armbruster, 2003; Armbruster \& de Souza, 2005). Species of Hypostomus belonging to the Hypostomus cochliodon group were recorded for the Brazilian portion of the rio Negro by Goulding et al. (1988), from the middle rio Negro area, and by Cabalzar et al. (2005) from the rio Tiquié (a tributary of rio Uaupés). The study of the material reported by these authors revealed that they are referable to two undescribed species, each of them characterized by a very distinctive color pattern. The aim of the present paper is to describe these species. 


\section{Material and Methods}

Measurements were made with digital calipers to the nearest $0.1 \mathrm{~mm}$. Counts and measurements follow Boeseman (1968) and Weber (1985). Plate counts and nomenclature follow schemes of serial homology proposed by Schaefer (1997), with the modifications of Oyakawa et al. (2005). A specimen was cleared and stained for cartilage and bone following the protocol of Taylor \& van Dyke (1985). Institutional abbreviations follow the online version of Catalog of Fishes (http://research.calacademy.org/research/ichthyology/ catalog/collections.asp).

\section{Hypostomus kopeyaka, new species Figs. 1-2}

Hypostomus sp.: Cabalzar et al., 2005: 101, 224 (Brazil, Amazonas, upper rio Tiquié: short description, ecological notes, horizontal distribution along the rio Tiquié).

Holotype. MZUSP 98764, 226.1 mm SL, Brazil, State of Amazonas, rio Tiquié, Serra do Mucura village, $0^{\circ} 10^{\prime} \mathrm{N} 69^{\circ} 07^{\prime} \mathrm{W}, 30 \mathrm{Aug}-12$ Sep 2006, F. C. T. Lima.

Paratypes. All from Brazil, State of Amazonas, rio Negro basin: MZUSP 92186, 1, $155.2 \mathrm{~mm} \mathrm{SL}$, igarapé Castanha, tributary of rio Tiquié, sand beach on Santa Rosa village, $0^{\circ} 04^{\prime} 41^{\prime \prime N} 69^{\circ} 41^{\prime 2} 26^{\prime \prime} \mathrm{W}$, 3-4 Oct 2006, F. C. T. Lima. MZUSP 92485, 1, 188.3 mm SL, igarapé Castanha, tributary to rio Tiquié, São Lourenço village, 008'34”N 69³6'31'W, 2 Sep 2006, F. C. T. Lima. MZUSP 93074 , 1, $157.8 \mathrm{~mm} \mathrm{SL}$, igarapé Castanha, tributary to rio Tiquié, surroundings of Sítio São Pedro, $0^{\circ} 11^{\prime}$ N 69³ $35^{\prime} \mathrm{W}, 14-30$ Nov 2006 , F. C. T. Lima.

Additional material (non-types). All from Brazil, State of Amazonas, rio Negro basin: MZUSP 64362, 1, 112.1 mm SL, igarapé Umari Norte, tributary to rio Tiquié, São Pedro village, $0^{\circ} 15^{\prime} 41^{\prime \prime} \mathrm{N}$ 6957'23”'W, 25-27 Oct 2000, F. C. T. Lima et al. MZUSP 81151, 1, $123.8 \mathrm{~mm}$ SL, c\&s, rio Tiquié, between Caruru and Boca de Sal villages, 0¹6'N 6954'W, 2001-2002, M. C. Lopes et al. MZUSP $81500,1,138.2 \mathrm{~mm}$ SL, rio Tiquié, São Pedro village, $0^{\circ} 16$ '04'N 69²8'51'W, 2001-2002, A. A. Barbosa. MZUSP 81522, 1, 164.2 $\mathrm{mm}$ SL, rio Tiquié, Caruru village, pool below the waterfall, 0¹6'29'N 6954'54'W, 21-22 Oct 2002, F. C. T. Lima et al. MZUSP 92181, 1, $166.3 \mathrm{~mm}$ SL and NUP 8019, 1, $140.4 \mathrm{~mm}$ SL, igarapé Castanha, tributary of rio Tiquié, sand beach at Santa Rosa village, 0 04'41"N 6941'26"W, 3-4 Oct 2006, F. C. T. Lima et al. MZUSP $92330,1,167.0 \mathrm{~mm}$ SL, rio Tiquié, Pirarara-Poço village, $0^{\circ} 08^{\prime} \mathrm{N}$ $69^{\circ} 12^{\prime}$ W, 6-14 Sep 2006, F. C. T. Lima, M. C. Lopes et al. MZUSP 93012, 1, $27.4 \mathrm{~mm} \mathrm{SL}$, igarapé Castanha, tributary to rio Tiquié, Santa Rosa indian village, $0^{\circ} 04^{\prime}$ N $69^{\circ} 41^{\prime}$ W, 27-30 Nov 2006, F. C. T. Lima et al.

Diagnosis. Hypostomus kopeyaka is distinguished from all Hypostomus species, except those belonging to the Hypostomus cochliodon group, by having few teeth (10 to 13) bearing a small lateral cusp and acutely angled dentaries. It is distinguished from the remaining members of the
Hypostomus cochliodon group, except $H$. hemicochliodon, $H$. sculpodon, H. soniae Hollanda, Carvalho \& Weber, and $H$. weberi, by possessing bicuspid teeth with mesial cusp rounded, considerably larger than outer cusp (vs. teeth generally unicuspid, outer cusp, if present, almost imperceptible, mesial cusp large and distinctly spoon-shaped). Hypostomus kopeyaka can be distinguished from $H$. hemicochliodon, H. sculpodon, H. soniae, and $H$. weberi by a distinctive color pattern composed of conspicuously horizontally elongated, closely-set black spots on the head and dorsal surfaces of the body ( $v s$. spots absent in H. soniae, spots present but rounded in the remaining species, spots small in H. hemicochliodon and H. sculpodon, and large and widely-set in $H$. weberi). Additionally, it is distinguished from all the members of the Hypostomus cochliodon group, except $H$. weberi, $H$. ericae Hollanda Carvalho \& Weber, $H$. hemicochliodon, $H$. paucipunctatus Hollanda Carvalho \& Weber, H. sculpodon and H. waiampi Hollanda Carvalho \& Weber, by possessing a buccal papilla. See the Discussion, for additional remarks on the diagnosis of Hypostomus kopeyaka.

Description. Meristic and morphometric data in Table 1. Overall view of body in Figs. 1 and 2. Dorsal profile slightly convex to straight from snout tip to interorbital area, convex from interorbital area to dorsal-fin origin, and almost straight from dorsal-fin origin to end of adipose fin. Ventral profile almost straight from snout tip to caudal fin. Caudal peduncle laterally compressed, roughly ovoid in cross section. Body width at cleithral region greater than head depth. Head broad and deep, covered dorsally with plates, except for naked area on snout tip. Median elongated bulge associated with mesethmoid terminating coequally with transversal through nares. Supraoccipital bone with conspicuous moderately to highly developed median ridge, and with relatively welldeveloped posterior process bordered by wide nuchal plate. A conspicuous ridge originating laterally to the nares, passing through supraorbital, and extending to posterior portion of pterotic-supracleithrum. Opercle small, with odontodes more developed distally. Oral disk round, medium-sized, lower lip not reaching transversal through gill openings, ventral surface covered with numerous small papillae decreasing in size posteriorly. Maxillary barbels moderately developed, about as long as orbital diameter. Horizontal patch of odontodes present over anterior surface of upper lip, just below the snout. Buccal papilla well-developed, its tip usually with granular surface. Jaws acutely angled, averaging less than $80^{\circ}$ between left and right dentaries rami. Eight to 16 (mode 14, holotype 16) teeth in premaxilla, seven to 14 (mode 12 , holotype 14) in dentary. Teeth bicuspid, curved inward distally, mesial cusp considerably larger than lateral cusp, rounded in shape (similar to the condition found in Hypostomus soniae, HollandaCarvalho \& Weber, 2004: fig. 4d, and H. hemicochliodon, Armbruster, 2003: fig. 1B).

Body covered with five rows of moderately spinulose dermal plates. Tip of snout mostly naked even in large 


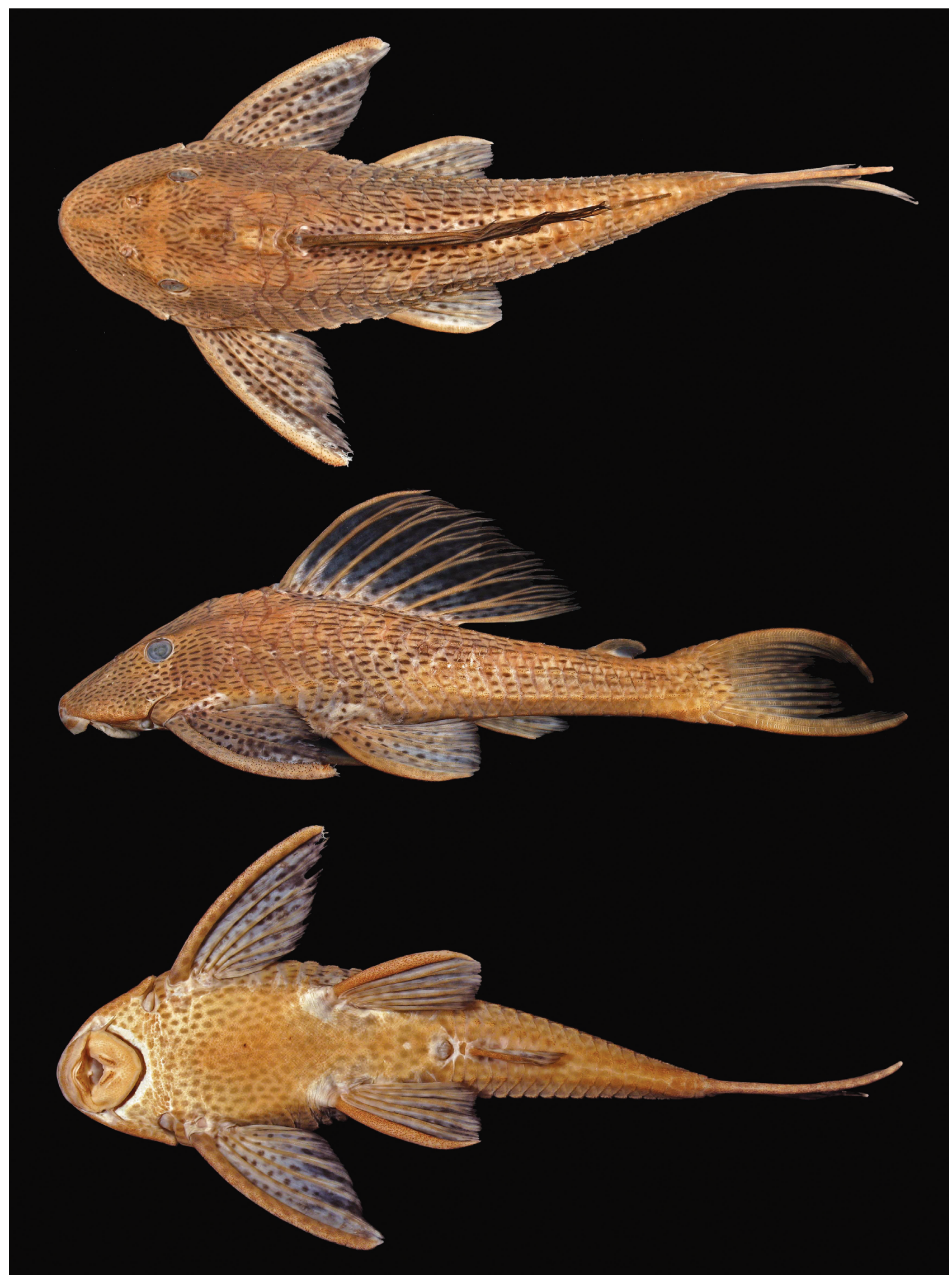

Fig. 1. Hypostomus kopeyaka, holotype, MZUSP 98764, 226.1 mm SL: dorsal, lateral, and ventral views. 


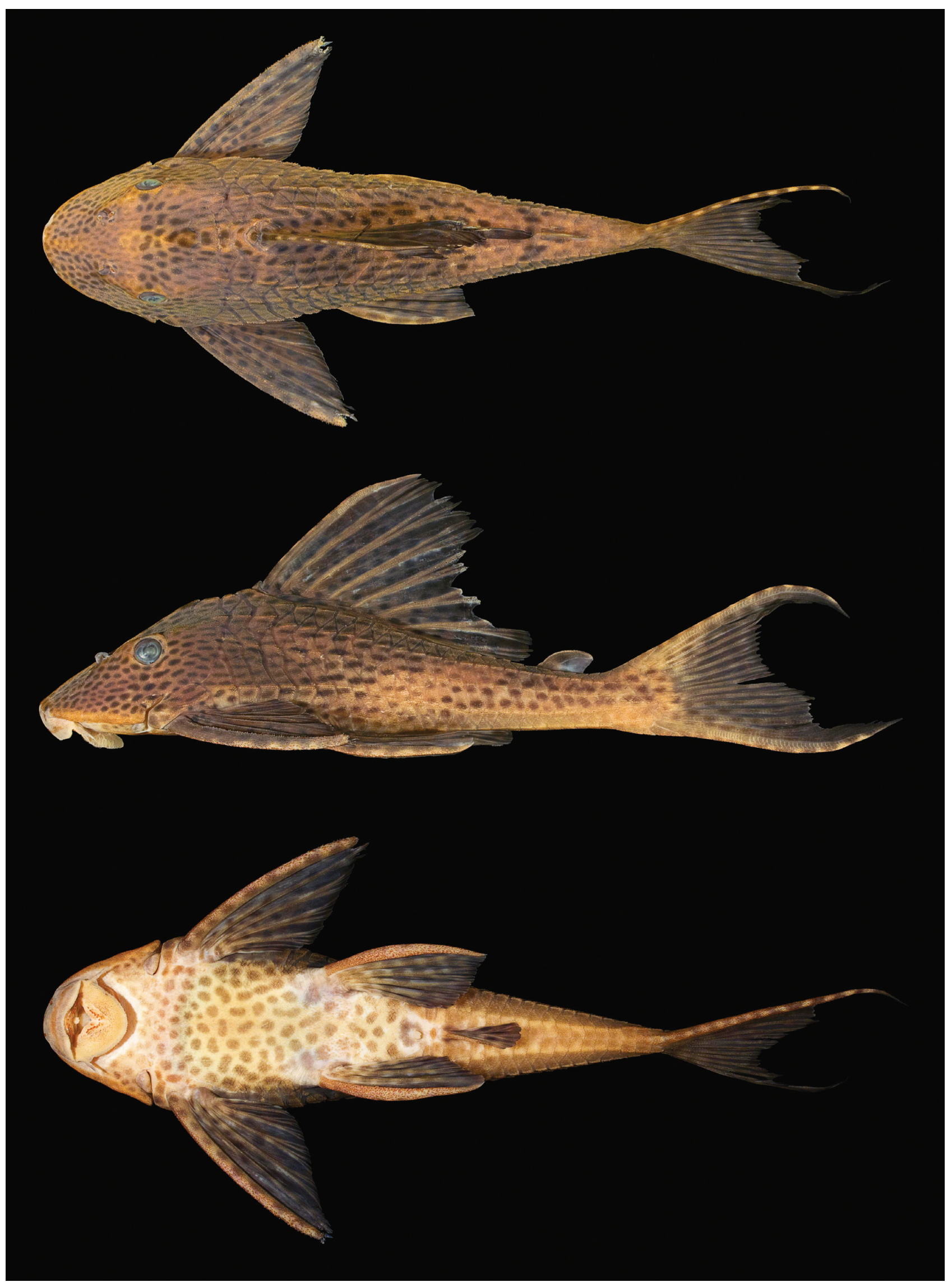

Fig. 2. Hypostomus kopeyaka, MZUSP 92330, 167.0 mm SL: dorsal, lateral, and ventral views. 
specimens, bearing two lateral vertical patches of odontodes. Dorsal-fin base naked. Predorsal region with two conspicuous keels, area between keels flat. Dorsal series of lateral plates with keel from first to third plate, displaced downward from fourth plate onwards, and extending to sixteenth to eighteenth dorsal plate. Mid-dorsal series of lateral plates with keel from first to third plate, slightly displaced downward from fourth plate onwards, and extending to $24^{\text {th }}$ to $27^{\text {th }}$ mid-dorsal plate. Median series of plates with moderately-developed keel and bearing lateral line. Mid-ventral series of plates with keel more developed from the first to the fifth or sixth plate. Ventral series of plates with weakly-developed keel along corner of ventral and lateral surfaces, deflecting laterally in the latter 5 to 6 plates. Ventral surface of head covered with platelets, with exception to the region around lower lip. Abdomen completely covered with minute platelets in specimens larger than $150 \mathrm{~mm} \mathrm{SL}$, with exception of small areas around pectoraland pelvic-fin insertions and at urogenital opening. Preanal plate present, exposed in all specimens except MZUSP 64362 (112.1 mm SL). Twenty-four to 25 (mode 24) dorsal plates, 26 to 29 (mode 27) mid-dorsal plates, 27 to 28 (mode 28) median plates, 28 to 29 (mode 28) mid-ventral plates, 22 to 24 (mode 23) ventral plates. Three predorsal plates, eight to nine plates below dorsal fin (mode 8), seven to eight preadipose plates (mode 8), seven to eight plates between adipose fin and caudal fin (mode 8), 14 to 15 plates between anal fin and caudal fin (mode 14).

Dorsal-fin II,7, its origin at vertical through midpoint between pectoral and pelvic fins, or slightly posterior to that point. Dorsal-fin margin convex. Adipose-fin spine compressed and curved inward. Pectoral fin I,6, its posterior border straight. Pectoral-fin spine slightly curved inward, covered with weakly developed odontodes, a little more developed on its distal portion in larger specimens. Tip of adpressed pectoral fin reaching one-third pelvic-fin spine length. Pelvic-fin i,5, its posterior border straight to slightly roundish. Pelvic-fin spine just surpassing anal-fin origin when adpressed. Anal fin i,4, its tip reaching the sixth or seventh plate after its origin. Rays of anal fin progressively increasing in size, third branched ray usually the longer. Caudal-fin margin concave, i, 14,i, with inferior lobe longer than superior one.

Color in alcohol. Color description based only on type series. Overall ground color of body and fins beige. Overall ground of ventral area lighter, cream colored in some specimens. Dorsal surface of head and body entirely covered by numerous thin, horizontally elongated, closely-set black spots, smaller and more rounded on head and larger and more elongated along body. These spots occasionally coalesce at midbody, forming narrow, short stripes. Darks spots posteriorly becoming faded and less elongated. Ventral surface of body, from immediately posterior to oral disk to urogenital opening with numerous, small, rounded dark blotches. Ventral blotches coalescing into wavy stripes in abdominal area of one paratype (MZUSP 93074). Overall ground color of fin rays beige, interradial membranes translucent. Dorsal-, pectoral-, and pelvic- fins with rounded, small dark blotches, arranged in rows along

Table 1. Morphometric data of Hypostomus weberi (holotype and paratypes) and H. kopeyaka (type series, including holotype and paratypes, and non-type specimens).

\begin{tabular}{|c|c|c|c|c|c|c|c|c|c|c|c|}
\hline & \multicolumn{4}{|c|}{ Hypostomus weberi } & \multicolumn{4}{|c|}{$\begin{array}{l}\text { Hypostomus kopeyaka } \\
\text { (type series) }\end{array}$} & \multicolumn{3}{|c|}{$\begin{array}{c}\text { Hypostomus kopeyaka } \\
\text { (non-types) }\end{array}$} \\
\hline & $\mathrm{n}$ & Holotype & Range & Mean+SD & $\mathrm{n}$ & Holotype & Range & Mean+SD & $\mathrm{n}$ & Range & Mean + SD \\
\hline \multicolumn{11}{|c|}{ Percents of standard length } & - \\
\hline Predorsal distance & 10 & 38.9 & $37.5-40.6$ & $39.0 \pm 1.2$ & 4 & 37.2 & $37.2-38.7$ & $38.0 \pm 0.6$ & 7 & $36.9-39.0$ & $38.0 \pm 0.7$ \\
\hline Head length & 10 & 32.8 & $31.6-34.8$ & $32.9 \pm 1.2$ & 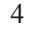 & 30.5 & $30.4-32.4$ & $31.2 \pm 1.0$ & 7 & $30.3-32.6$ & $31.9 \pm 0.8$ \\
\hline Dorsal-fin spine length & 6 & 32.0 & $29.9-37.8$ & $33.8 \pm 2.9$ & 4 & 27.7 & $27.7-30.4$ & $29.1 \pm 1.3$ & 6 & $29.2-33.0$ & $30.9 \pm 1.4$ \\
\hline Dorsal-fin base length & 10 & 29.8 & $27.0-30.2$ & $28.9 \pm 1.0$ & 4 & 28.0 & $28.0-28.8$ & $28.3 \pm 0.4$ & 7 & $26.5-29.0$ & $28.0 \pm 0.9$ \\
\hline Interdorsal length & 10 & 20.4 & $17.1-21.1$ & $18.9 \pm 1.4$ & 4 & 21.4 & $20.8-21.9$ & $21.4 \pm 0.4$ & 7 & $18.5-21.6$ & $20.1 \pm 1.0$ \\
\hline Thoracic length & 10 & 25.7 & $19.1-26.2$ & $23.8 \pm 2.0$ & 4 & 22.7 & $21.9-25.2$ & $23.5 \pm 1.5$ & 7 & $23.9-27.2$ & $24.9 \pm 1.2$ \\
\hline Pectoral-fin spine length & 10 & 32.9 & $31.5-32.9$ & $32.3 \pm 0.5$ & 4 & 33.3 & 29.9-33.5 & $32.5 \pm 1.7$ & 7 & $27.8-34.3$ & $31.3 \pm 2.2$ \\
\hline Abdominal & 10 & 20.2 & 18.9-21.4 & $20.6 \pm 0.7$ & 4 & 20.3 & $20.3-21.8$ & $20.8 \pm 0.7$ & 7 & $19.6-22.1$ & $20.7 \pm 0.8$ \\
\hline Pelvic-f & 10 & 26.5 & $23.9-27.6$ & $25.5 \pm$ & 4 & 22.9 & $22.5-25.2$ & $23.8 \pm 1.3$ & 7 & 7.2 & $24.0 \pm 1.8$ \\
\hline gth & 10 & 31. & 4 & 3 & 4 & 33.1 & .1 & 32. & 7 & .0 & $32.7 \pm 1.3$ \\
\hline cle depth & 10 & 9.9 & $1-10.0$ & $7 \pm 0.3$ & 4 & 8.8 & 8-8.9 & $8.6 \pm 0.5$ & 7 & 8 & $.4 \pm 0.3$ \\
\hline Anal-fin width & 10 & 17.7 & 17.1-19.4 & $17.6 \pm 0.7$ & 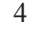 & 15.9 & $9-16.8$ & $16.4 \pm 0.4$ & 7 & 1.0 & $8.3 \pm 2.2$ \\
\hline Folded & 10 & 45.8 & .2 & 1 & & 46.3 & 7.1 & 45. & t & 4.1 & $44.6 \pm 5.9$ \\
\hline Sno & 10 & 24.3 & $24.1-26.1$ & $24.7 \pm$ & & 22.3 & $21.4-22.7$ & $22.2 \pm$ & 7 & 5.5 & $23.2 \pm 2.4$ \\
\hline Dorsal-caudal le & 10 & 33.2 & $31.6-37.1$ & $34.1 \pm 1.8$ & 4 & 36.3 & $36.3-37.9$ & $37.0 \pm 0.7$ & 7 & $30.8-43.4$ & $36.2 \pm 4.3$ \\
\hline Upper caudal ray length & & & & & & 27.6 & & & 7 & $27.5-45.5$ & $39.3 \pm 6.0$ \\
\hline Lower caudal ray length & & & & & & 30.0 & & & 7 & $41.7-49.0$ & $44.6 \pm 3.2$ \\
\hline Cleithral width & 10 & 30.8 & $29.8-32.0$ & $31 . \overline{1} \pm 0$ & 4 & 28.1 & $27.1-28.1$ & $27 . \overline{6}+0.5$ & 7 & $25.0-28.6$ & $26.5 \pm 1.2$ \\
\hline Head depth & 10 & 22.9 & $21.6-24.2$ & $23.0 \pm 0.7$ & 4 & 20.4 & $20.4-21.6$ & $20.9 \pm 0.6$ & 7 & $19.3-21.6$ & $20.7 \pm 0.8$ \\
\hline \multicolumn{12}{|l|}{ Percents of head length } \\
\hline Snout length & 10 & 63.3 & $59.4-64.0$ & $61.9 \pm$ & 4 & 62.1 & $58.0-62.1$ & $60.7 \pm$ & 7 & 2.6 & $60.3 \pm 1.6$ \\
\hline Orbital diameter & 10 & 20.0 & 19.5-23.0 & $20.8 \pm 1.0$ & 4 & 16.0 & $16.0-18.5$ & $17.4 \pm 1.1$ & 7 & $16.8-19.5$ & $18.5 \pm 1.1$ \\
\hline Intero & 10 & 50.0 & $47.2-52.7$ & $50.7 \pm 1.5$ & 4 & 45.4 & $45.4-51.2$ & $47.3 \pm 2.7$ & 7 & $45.0-51.5$ & $48.3 \pm 2.1$ \\
\hline Dentary length & 10 & 12.5 & $11.8-13.6$ & $12.6 \pm 0.7$ & 4 & 12.0 & $11.3-12.3$ & $11.8 \pm 0.4$ & 7 & $10.6-12.5$ & $11.6 \pm 0.7$ \\
\hline \multicolumn{12}{|c|}{ Percents of caudal peduncle length } \\
\hline Caudal-peduncle depth & 10 & 30.2 & $28.6-32.1$ & $31.0 \pm 1.1$ & & 26.7 & 23.9-27.9 & $26.4 \pm 2.2$ & 7 & $24.2-27.0$ & $25.8 \pm 1.0$ \\
\hline Adipose-fin spine length & 10 & 24.9 & $23.3-29.0$ & $25.9 \pm 1.8$ & 4 & 23.9 & $20.6-24.2$ & $22.5 \pm 1.8$ & 7 & $20.6-25.0$ & $22.0 \pm 1.7$ \\
\hline
\end{tabular}


interradial membranes. Dorsal-, pectoral-, and pelvic- fin spines each with series of relatively faded dark blotches. Anal fin with faded, rounded blotches along interradial membranes. Faded blotches along adipose-fin spine. Caudal fin displaying several vertical rows of faded dark blotches.

Variation. Specimens listed above as non-types exhibit overall ground color dark-brown to chestnut, instead of the beige color pattern present in the type series (compare Figs. 1 and 2). Also, these specimens possess dark blotches larger and less numerous when compared to lighter-colored specimens, and ventral blotches larger and often coalescing into wavy stripes. These specimens were thus considered non-types, although no differences in morphometric or meristic features were found between the lighter, typical specimens and nontypical, darker specimens.

Distribution. Hypostomus kopeyaka is known only from the rio Tiquié basin, a tributary of the rio Uaupés, upper rio Negro drainage, Brazil (Fig. 4). According to Tuyuka fishermen, the species also occurs at the upper rio Tiquié into Departamento Vaupés in Colombia, but no specimens are available from the latter area.

Ecological notes. Hypostomus kopeyaka was collected in rapids, cataract pools, and slow-flowing portions of the rio Tiquié and some large tributaries (igarapé Umari Norte, and igarapé Castanha). No clear habitat preference was identified, though most specimens were collected in relatively slowflowing portions of the rio Tiquié itself or at its large whitewater tributary, the igarapé Castanha.

Etymology. After its common name among the Tuyuka and Tukano indians, kope yaka, or kope ya'ka, meaning "pleco from the holes", an allusion to the fact that, according to the Indians, the fishes spend most of their time hiding in holes in the river banks (Cabalzar et al., 2005).

\section{Hypostomus weberi, new species Fig. 3}

Cochliodon sp.: Goulding et al., 1988: 128, 141 (rio Negro basin, Brazil; diet, habitat).

Holotype: MZUSP 98767, 149.3 mm SL, Brazil, Amazonas, Barcelos, rio Negro, $0^{\circ} 58^{\prime}$ 'S $62^{\circ} 57^{\prime} \mathrm{W}, 2$ Feb 1980, M. Goulding.

Paratypes: All from Brazil, State of Amazonas, rio Negro basin: MZUSP 34598, 2, 141.8-162.8 mm SL, same data as holotype. MZUSP 34604, 5, 107.0-174.5 mm SL, NUP 6344, 1, $156.6 \mathrm{~mm}$ SL, rio Marauiá, near the mouth, "igapó" (= flooded forest), $0^{\circ} 24$ 'S 65'12'W, 27 May 1979, M. Goulding. MZUSP 34765, 1, 152.1 $\mathrm{mm}$ SL, rio Negro, below rio Daraá, "pedral” (= rapids), $0^{\circ} 28^{\prime} \mathrm{S}$ 64²6’W, 16 Feb 1980, M. Goulding.

Additional material (non-types): MNRJ 1066, 1, $151.3 \mathrm{~mm}$ SL, "rio Cicipa, limite Brasil-Venezuela" [sic]; March 1933, C. Lako.
NRM 17079, 1, 158.1 mm SL, "Brazil or Peru, rio Amazonas or rio Negro drainages”, 1923-1925, D. Melin et al.

Diagnosis. Hypostomus weberi is distinguished from all Hypostomus species, except those belonging to the Hypostomus cochliodon group, by having few teeth bearing a small outer cusp (10 to 13) and acutely angled dentaries. It is distinguished from the remaining members of the Hypostomus cochliodon group, except $H$. hemicochliodon, H. kopeyaka, H. sculpodon, and H. soniae, by possessing bicuspid teeth with mesial cusp rounded, considerably larger than outer cusp ( $v s$. teeth generally unicuspid, outer cusp, if present, almost imperceptible, mesial cusp large and distinctly spoon-shaped). Hypostomus weberi can be distinguished from $H$. hemicochliodon, H. kopeyaka, H. sculpodon, H. soniae, and $H$. weberi by its unique color pattern, with large, black, rounded spots widely-spaced and sharply defined, on the head, dorsal surface and fins (vs. spots absent in H. soniae, spots present in the remaining species, elongated and closelyset in $H$. kopeyaka, and small and rounded in $H$. hemicochliodon and H. sculpodon). Additionally, it is distinguished from all the members of the Hypostomus cochliodon group, except $H$. kopeyaka, $H$. ericae, $H$. hemicochliodon, $H$. paucipunctatus, $H$. sculpodon and $H$. waiampi, by having a buccal papilla. See the Discussion, for additional remarks on the diagnosis of Hypostomus weberi.

Description. Meristic and morphometric data in Table 1. Overall view of body in Fig. 3. Dorsal profile slightly convex to straight from snout tip to interorbital area, highly convex from interorbital area to dorsal-fin origin, and almost straight from dorsal-fin origin to end of adipose fin. Ventral profile almost straight from snout tip to caudal fin. Caudal peduncle laterally compressed, roughly ovoid in cross section. Body width at cleithral region greater than head depth. Head broad and deep, covered dorsally with plates, except for small naked area on snout tip. Median elongate bulge associated with mesethmoid, terminating coequally with transversal through nares. Supraoccipital bone with conspicuous highly developed median ridge, and with well-developed posterior process bordered by wide nuchal plate. Conspicuous ridge originating laterally to the nares, passing through supraorbital, and extending to posterior portion of pterotic-supracleithrum. Opercle medium to large, with odontodes more developed distally. Oral disk round, medium-sized, lower lip not reaching transversal through gill openings, ventral surface covered with numerous small papillae decreasing in size posteriorly. Maxillary barbels moderately developed, about the same size as orbital diameter. Anterior surface of upper lip covered with odontodes, continuous with patch of odontodes on snout. Buccal papilla medium to large-sized. Jaws acutely angled, averaging less than $80^{\circ}$ between left and right dentaries rami. Ten to 12 (mode 12, holotype 11) teeth in premaxilla, ten to 13 (mode 11, holotype 13) in dentary. Teeth bicuspid, curved inward distally, mesial cusp considerably larger than lateral cusp, rounded in shape (similar to the condition found in 


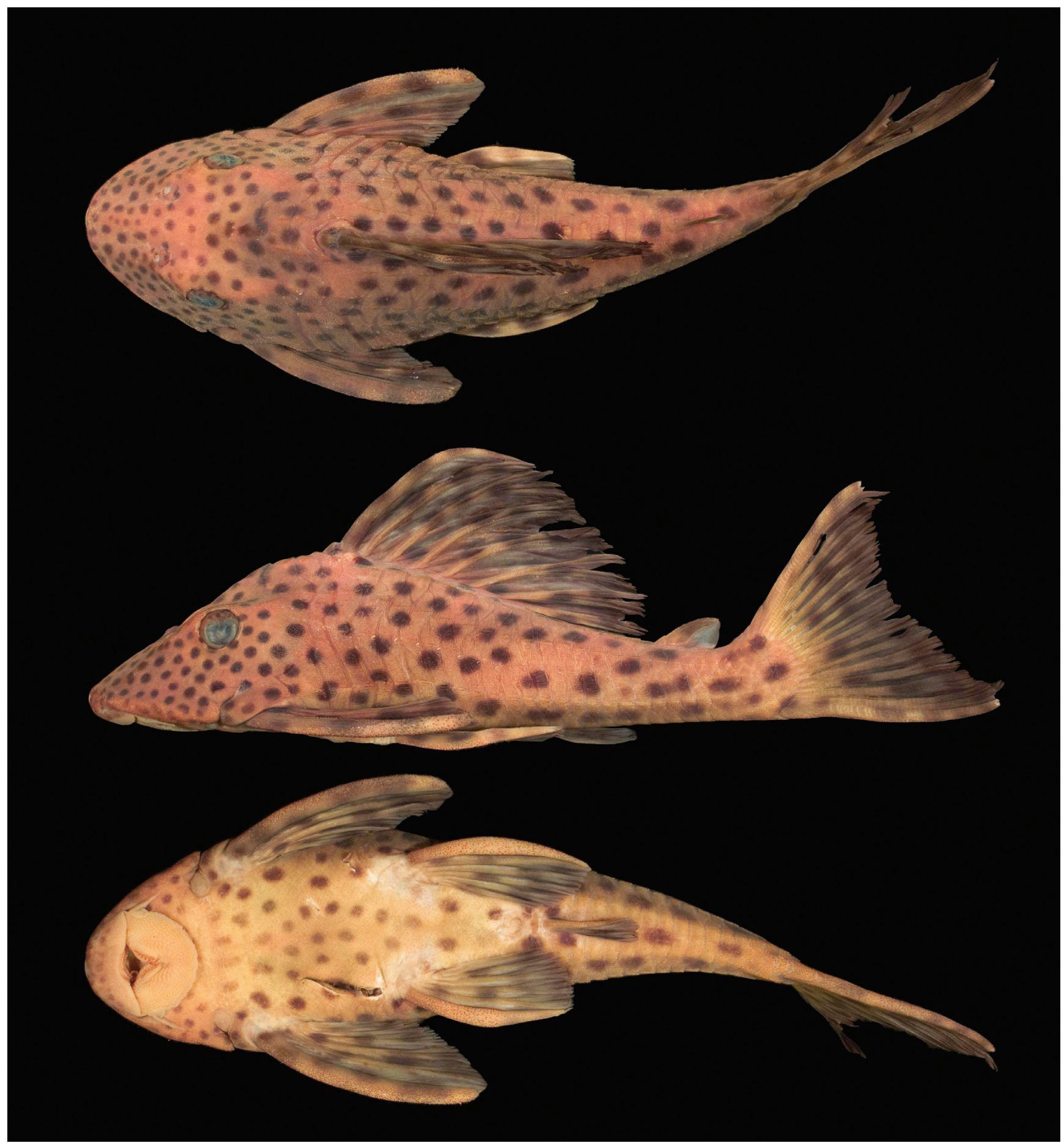

Fig. 3. Hypostomus weberi, holotype, MZUSP 98767, $149.3 \mathrm{~mm}$ SL: dorsal, lateral, and ventral views.

Hypostomus soniae, Hollanda-Carvalho \& Weber, 2004: fig. 4d, and H. hemicochliodon, Armbruster, 2003: fig. 1B).

Body covered with five rows of moderately spinulose dermal plates. Small naked area on snout tip, about the size of the nares. Dorsal-fin base naked. Predorsal region with two conspicuous keels, area between keels flat. Dorsal series of lateral plates with keel from first to third plate, displaced downward from fourth plate onwards, and extending to sixteenth to seventeenth dorsal plate. Mid-dorsal series of lateral plates with keel from first to third plate, slightly displaced downward from fourth plate onwards, and extending to $26^{\text {th }}$ to $27^{\text {th }}$ mid-dorsal plate. Median series of plates with moderately-developed keel and bearing lateral line. Midventral series of plates with keel more developed from the first to the fifth or sixth plate. Ventral surface of head covered with minute platelets, with exception to the region beneath 
lower lip. Abdomen completely covered with minute platelets in specimens larger than $135 \mathrm{~mm} \mathrm{SL}$, with exception of small areas around pectoral- and pelvic-fin insertions and at urogenital opening. Preanal plate present, wide. Twenty-three dorsal plates, 26 to 28 (mode 27) mid-dorsal plates, 26 to 28 (mode 27) median plates, 27 to 28 (mode 28) mid-ventral plates, 22 to 23 (mode 23) ventral plates. Three predorsal plates, eight plates below dorsal fin, seven plates between dorsal fin and adipose fin, eight plates between adipose fin and caudal fin, 13 to 14 plates between anal fin and caudal fin (mode 14).

Dorsal-fin II, 7, its origin situated approximately at midpoint between pectoral and pelvic fins, or slightly posterior to that point. Dorsal-fin margin convex. Adipose-fin spine compressed and curved inward, straight in smaller specimens. Pectoral fin $\mathrm{i}, 6$, its posterior border straight. Pectoral-fin spine slightly curved inward, covered with weakly developed odontodes, considerably more developed on its distal portion in larger specimens. Tip of adpressed pectoral fin reaching one-third pelvic-fin spine length. Pelvic-fin I,5, its posterior border straight to slightly rounded. Pelvic-fin spine just surpassing anal-fin origin when adpressed. Anal fin i,4, its tip reaching the fourth or fifth plate after its origin. First to third branched anal-fin rays similar in size, unbranched and fourth branched rays slightly smaller. Caudal-fin margin concave, i, 14,i, with inferior lobe longer than superior one.

Color in alcohol. Overall ground color of body and fins chestnut-brown to dark-brown lighter on ventral surface. Dorsal surface of head and body entirely covered by rounded, large dark spots, more numerous, smaller and closely-set on head, larger and widely-set on trunk and ventral area. Caudal peduncle spots elongated in some specimens. Abdominal spots coalescing into larger spots in some specimens. Spots on fins usually uniformly distributed, except on caudal fin which is often devoid of spots on its base.

Distribution. Hypostomus weberi is known from the middle rio Negro area at Barcelos and its tributary, the rio Marauiá (Fig. 4). There is a single poorly preserved specimen (MNRJ 1066), apparently belonging to this species, recorded from an uncertain locality, "rio Cicipa", said to be at the Brazilian/ Venezuelan border. There is no "rio Cicipa" in the upper rio Negro area in Brazil, and this locality is certainly misspelled. It is possible that "rio Cicipa" correspond to río Siapa, a tributary of the río Casiquiare in Venezuela. That suggests that Hypostomus weberi is distributed farther upstream into the upper rio Negro, an assumption that need to be corroborated with further collecting in the area. The specimen NRM 17079, whose exact provenience is also uncertain, was very probably collected somewhere in the rio Negro basin in Brazil, an area visited by the collector of the species, the herpetologist Douglas Melin, between 1923-1924 (Melin, 1941). Specimens MNRJ 1066 and NRM 17079 were thus not included in the type series both because of their uncertain locality data and poor state of preservation.
Ecological notes. Goulding et al. (1988: 141) mentions detritus as the principal food item found in gut contents of four specimens of Hypostomus weberi (as Cochliodon sp.). Specimens of Hypostomus weberi were reported as being collected both at rapids ("pedral") and flooded forest ("igapó").

Etymology. The name weberi, after Claude Weber, from the Muséum d'Histoire Naturelle de Génève, for his contributions to the knowledge of the genus Hypostomus.

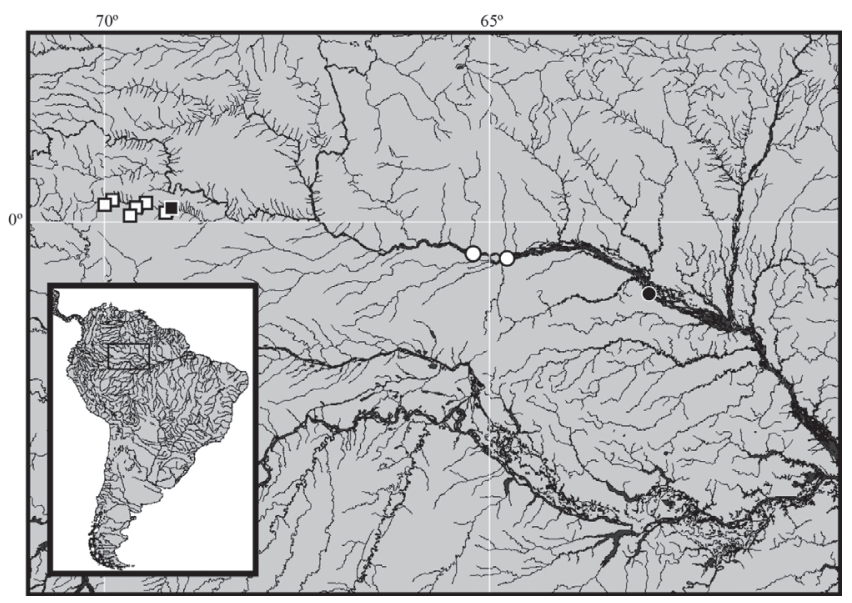

Fig. 4. Map of northern South America, showing distributions of Hypostomus kopeyaka (squares) and Hypostomus weberi (dots). Black symbols refer to type-localities.

\section{Discussion}

Both Hypostomus species described in this paper are mainly diagnosed from their congeners by their unusual coloration. The conspicuously horizontally elongated, closely-set black spots over the body displayed by Hypostomus kopeyaka resembles the color pattern found in Hypostomus micromaculatus Boeseman and, to a lesser extent, $H$. crassicauda Boeseman. However, $H$. micromaculatus possess spots that are considerably smaller, more closely-set, and more numerous than those present in H. kopeyaka (compare Fig. 5 with Figs. 1-2), whereas $H$. crassicauda possess numerous, small spots that are ellipsoid in shape. Hypostomus weberi have large black, rounded spots, widely spaced over a lighter background, covering the entire dorsal surface of the body and fins. Although there are some other Hypostomus species displaying relatively large dark blotches over the body (e.g., $H$. hermanii Ihering, $H$. mutucae Knaack, and $H$. paucimaculatus Boeseman), apparently none of them possess blotches as large, sharply-defined, and widely spaced as those present in $H$. weberi. None of the aforementioned Hypostomus species belong to the $H$. cochliodon group (see Armbruster, 2003, for the 
synapomorphies that diagnose the group), hence there are no grounds to suspect that either $H$. kopeyaka or $H$. weberi might be closely related to any of them.

The rio Negro basin is inhabited by at least five species of Hypostomus belonging to the Hypostomus cochliodon group: H. hemicochliodon, H. kopeyaka, H. macushi, H. sculpodon, and $H$. weberi. Hypostomus hemicochliodon and $H$. sculpodon possess a color pattern that is superficially similar to the one displayed by H. kopeyaka. However, Hypostomus hemicochliodon and $H$. sculpodon possess rounded small spots that can become elongated posteriorly on body, against the distinctly elongated spots over the head and dorsolateral surfaces of body found in H. kopeyaka. On other hand, Hypostomus macushi possess a color pattern that recalls the one found in H. weberi. Hypostomus macushi displays smallto middle-sized rounded dark spots over the head and dorsolateral surfaces of body (see Armbruster \& de Souza, 2005, fig. 1), versus the large spots displayed by $H$. weberi. Additionally, as mentioned in the Diagnosis, Hypostomus macushi lacks the buccal papilla, which is present in $H$. weberi, and possess the derived teeth shape condition in the Hypostomus cochliodon group, viz., spoon-shaped, with the outer cusp very small or absent, versus the intermediate, plesiomorphic condition (sensu Armbruster, 2003) found in $H$. weberi, i.e., bicuspid teeth, with the mesial cusp rounded and considerably larger than the lateral cusp but not spoonshaped.

The two color morphs of Hypostomus kopeyaka are considered by the Tukano Indians from the middle rio Tiquié as representing distinct species. Although there are consistent differences in color pattern, we were unable to identify any other character distinguishing both morphs, and we consider them tentatively as conspecific. Collecting of additional material of the species, as well as analysis of molecular data, are necessary to clarify this question.

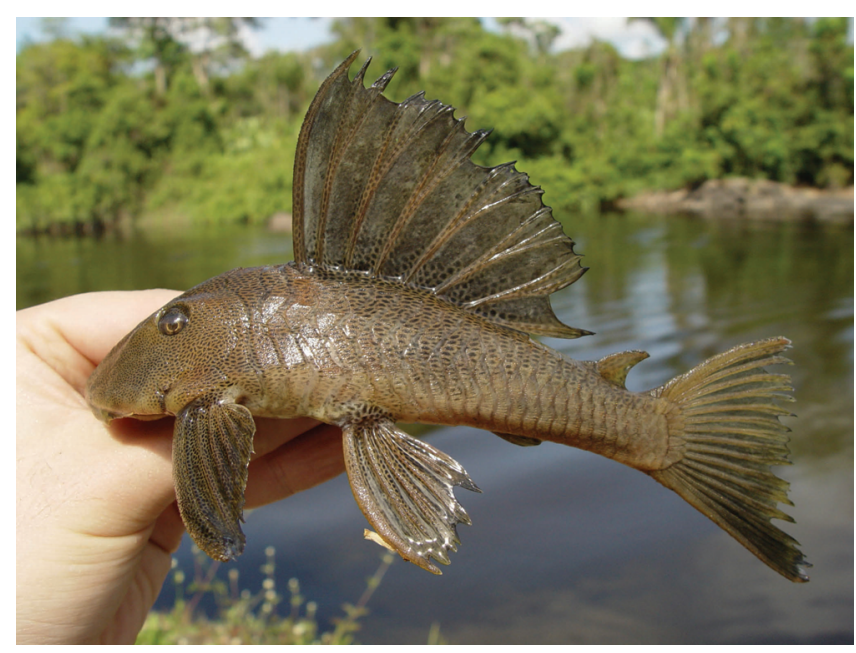

Fig. 5. Hypostomus micromaculatus, MHNG 2674.028, 143.1 $\mathrm{mm}$ SL, Suriname, Gran River at Kossindo, Cajana.
Comparative material examined. Hypostomus cochliodon: NMW 44101, $176.2 \mathrm{~mm}$ SL, syntype. H. crassicauda: RMNH 25489, $139.4 \mathrm{~mm}$ SL, holotype. H. ericae: MHNG 2650.026, $130.5 \mathrm{~mm}$ SL, paratype. H. ericius: ANSP 176149, $104.0 \mathrm{~mm}$ SL, paratype. $H$. fonchii: MHNG 2613.066, $141.0 \mathrm{~mm}$ SL, holotype. $H$. hemicochliodon: ANSP 185320, $228.0 \mathrm{~mm}$ SL; H. hermanii: BMNH 1905.6.9.5, $201.8 \mathrm{~mm}$ SL, holotype; H. hondae: BMNH 1909.7.23.44, 59.1 mm SL, paratype; H. levis: UMSS 1721, 187.9 mm SL; H. macushi: AUM 35510, 1, 148.1 mm SL; AUM 45064, 1, 170.0 mm SL; H. micromaculatus: RMNH 25483, 171.0 mm SL, paratype; MHNG 2674.028, $143.1 \mathrm{~mm} \mathrm{SL}$; H. mutucae: MCP 28669, 67.1 mm SL, holotype; MZUSP 99290, 6, 59.0-96.8 mm SL; MZUSP 27694, 2, 75.3-79.3 mm SL. H. oculeus: FMNH 106015, 130.0 mm SL; H. paucipunctatus: MHNG 2652.017, (2) 135.6-155.0 mm SL, paratypes; H. plecostomoides: CAS 12694, 214.0 mm SL; H. pyrineusi: MNRJ 863, 204.0 mm SL, holotype; ANSP 180718, (2) 38.6-175.0 mm SL; H. sculpodon: AUM 39476, 1 of 2, $220 \mathrm{~mm}$ SL; AUM 40220, 1, 229 mm SL; AUM 42188, 4 of 7, 219-264 mm SL; H. simios: MHNG 2652.018, $112.0 \mathrm{~mm} \mathrm{SL}$, paratype; H. soniae: MHNG 2547.012, (13) 35.4-143.0 mm SL, paratypes; H. taphorni: AMNH 13664, $189.0 \mathrm{~mm} \mathrm{SL}$; H. waiampi: MHNG 2652.016, 174.4 mm SL, paratype.

\section{Ackowledgements}

We are grateful to Paulo A. Buckup (MNRJ), Sven Kullander and Bodil Kajrup (NRM), Jonathan Armbruster and David Werneke (AUM), for the loan of material. Eduardo Baena, for the preparation of the pictures, and Leandro Souza, who helped with the preparation of the map. Raphael Covain (MHNG) kindly provided the picture of $H$. micromaculatus. Material of Hypostomus kopeyaka was collected during expeditions for the project "Peixes e Pesca no alto Tiquié", a joint collaboration of Instituto Socioambiental (ISA), and Federação das Organizações Indígenas do Rio Negro (FOIRN), and Associação das Tribos Indígenas do Alto Rio Tiquié (ATRIART). We are grateful to Aloísio Cabalzar, Mauro Lopes, Carlos Alberto Ricardo, and the staff of ISA, FOIRN, and ATRIART for their help and assistance during the field expeditions. We owe special thanks to the Tukano and Tuyuka people from the rio Tiquié, especially Tarcísio, Feliciano, and Antenor, for their aid to FCTL during field trips. CHZ received travel grants from the All Catfishes Species Inventory (NSF DEB-0315663) for research in ichthyological collections in Europe and North America. The second author is financially supported by FAPESP (grant \# 07/02978-7).

\section{Literature Cited}

Albert, J. S., N. R. Lovejoy \& W. G. R. Crampton. 2006. Miocene tectonism and the separation of cis- and trans-Andean river basins: evidence from Neotropical fishes. Journal of South American Earth Sciences, 21(1-2): 14-27.

Armbruster, J. W. 2003. The species of the Hypostomus cochliodon group (Siluriformes: Loricariidae). Zootaxa, 249: 1-60.

Armbruster, J. W. \& L. de Souza. 2005. Hypostomus macushi, a 
new species of the Hypostomus cochliodon group (Siluriformes: Loricariidae) from Guyana. Zootaxa, 920: 1-12.

Boeseman, M. 1968. The genus Hypostomus Lacépède, 1803, and its Surinam representatives (Siluriformes: Loricariidae). Zoologische Verhandelingen, 99: 1-89.

Cabalzar, A., F. C. T. Lima \& M. C. Lopes. 2005. Peixes e gente no alto rio Tiquié: conhecimento tukano e tuyuka, ictiologia, etnologia. São Paulo, Instituto Socioambiental, 339p.

Eschmeyer, W. N. 1998. Catalog of fishes. San Francisco, California Academy of Sciences, 2905p.

Goulding, M., M. Leal Carvalho \& E. J. G. Ferreira. 1988. Rio Negro, rich life in poor water. Amazonian diversity and food chain ecology as seen through fish communities. The Hague, Netherlands, SPB Academic Publishing, 200p.

Hollanda Carvalho, P. \& C. Weber. 2004. Five new species of the Hypostomus cochliodon group (Siluriformes: Loricariidae) from middle and lower Amazon System. Revue Suisse de Zoologie, 111(4): 953-978.

Melin, D. 1941. Contributions to the knowledge of the Amphibia of South America. Göteborgs Kungl. Vetenskaps Och Vitterhets Samhälles Handligar, 1(4): 1-71.

Montoya-Burgos, J. I. 2003. Historical biogeography of the catfish genus Hypostomus (Siluriformes: Loricariidae), with implications on the diversification of the Neotropical ichthyofauna. Molecular Ecology, 12: 1855-1867.

Montoya-Burgos, J. I., C. Weber \& P. Y. Le Bail. 2002. Phylogenetic relationships within Hypostomus (Siluriformes: Loricariidae) and related genera based on mitochondrial D-loop sequences. Revue Suisse de Zoologie, 109(2): 369-382.

Oyakawa, O. T., A. Akama \& A. M. Zanata. 2005. Review of the genus Hypostomus Lacépède, 1803 from rio Ribeira de Iguape basin, with description of a new species (Pisces, Siluriformes, Loricariidae). Zootaxa, 921: 1-27.

Schaefer, S. A. 1997. The Neotropical cascudinhos: systematics and biogeography of the Otocinclus catfishes (Siluriformes: Loricariidae). Proceedings of the Academy of Natural Sciences of Philadelphia, 148: 1-120.

Taylor, W. R. \& G. C. van Dyke. 1985. Revised procedures for staining and clearing small fishes and other vertebrates for bone and cartilage study. Cybium, 9: 107-109.

Weber, C. 1985. Hypostomus dlouhyi, nouvelle espèce de poissonchat cuirassé du Paraguay (Pisces, Siluriformes, Loricariidae). Revue Suisse de Zoologie, 92(4): 955-968.

Weber, C. \& J. I. Montoya-Burgos. 2002. Hypostomus fonchii sp. n. (Siluriformes: Loricariidae) from Peru, a key species suggesting the synonymy of Cochliodon with Hypostomus. Revue Suisse de Zoologie, 109(2): 355-368.

Accepted November 24, 2009 Published March 31, 2010 